\title{
Evidence suggests a novel cerebrospinal circulatory system exists in human nerves.
}

\section{INTRODUCTION}

Evidence from a 5-year study including 150 fresh human cadaver dissections, microsurgery, fluorescent microinjections, immunohistochemistry and confocal imaging suggests a novel CSF circulatory system exists in human nerves. We introduced this system in $2017 .{ }^{1}$ Here we provide further evidence to support our conclusion. No previous manuscript, text, or atlas has identified a CSF circulatory system in nerves. ${ }^{2-22}$ The human nervous system is devoid of lymphatics. ${ }^{2-22}$

This entire study began with the observation of vessels traveling on outer nerve (i.e. epineurial vessels) during carpal tunnel surgery (Figures 1a and b). These vessels had not been previously described..$^{2-22}$ Our initial hypothesis was that epineurial vessels were part of the lymphatic system because they were devoid of red blood cells. This hypothesis turned out to be incorrect: we tried to characterize something "novel" in terms of what was already known (lymphatic vessels). In retrospect, this is probably the most important reason that the human CSF circulatory system has evaded detection until now: it is a novel system comprised of novel vessels. CSF vessels in humans likely predated the vascular circulation; they may be a remnant of the earliest circulatory system in multicellular organisms; and can be therefore characterized as priangeo (pri before; angeo vascular) vessels. 


\section{RESULTS}

Ten studies were performed, each addressing a specific question. Techniques

developed by Suami et al were adapted for this study. ${ }^{23-26}$ This manuscript uses

terminology proposed by Sunderland. ${ }^{20}$ Nerves and brain are covered by layers of fascia:

nerves by neurium; brain by meninges (singular meninx: membrane). Neurium and

meninges are embryologically analogous layers. Note: perineural means "surrounding the nerve"; perineurium means "surrounding nerve fascicles". The terms are not interchangeable.

\section{Are epineurial CSF vessels present on all nerves?}

We identified epineurial CSF vessels in all 54 median/ulnar nerve dissections (27

bilateral; 11f/16m; ages 58-98 years, mean 68.3). Epineurial CSF vessels travel along the entire length of nerves (Figures 1a and b). Epineurial CSF vessels communicate with adjacent lymphatics; the largest communications occur at sites of potential nerve compression (Figure 1c).

\section{Do epineurial CSF vessels have a defined lumen?}

\section{Dye injection confirmed that epineurial CSF vessels have a lumen in all 10 upper}

specimens tested (6f/2m; ages 46 to 97 years; mean 76.6) (Figure 2). It was possible to inject epineurial CSF vessels with some macromolecular dyes (e.g. India ink), however, fluorescent dyes exhibited better flow. 
medRxiv preprint doi: https://doi.org/10.1101/2020.06.26.20141267; this version posted June 29, 2020. The copyright holder for this preprint

(which was not certified by peer review) is the author/funder, who has granted medRxiv a license to display the preprint in perpetuity.

All rights reserved. No reuse allowed without permission.

\section{Do epineurial CSF vessels drain into thoracic duct?}

Vessels traveling from epineurial CSF vessels to the thoracic duct were identified in

all 13 hemi-thoracic cadaver dissections (5f/8m; ages 54-92; mean 74.3). Large

communicating vessels were reliably found along the T1 nerve root (Figure 3a). FITC

(fluoroscein isothiocyanate) injection in 2 specimens confirmed drainage into the thoracic duct. Epineurial CSF vessels on upper roots $(\mathrm{C} 5, \mathrm{C6})$ first drain to the cervical CSF system and from there to thoracic duct (Figure 3b).

\section{Do epineurial CSF vessels drain into lymphatics?}

Continuity between epineurial CSF vessels and the lymphatic system, and the superiority of fluorescent over visible dyes for imaging, was confirmed in all 8 upper extremity dissections (6f/2m; ages 52 to 92 years. Mean 83). Raters were unable to document dye traveling from lymphatic to nerve using ambient light ( $0 \%$ of responses) (Figure 4a). Raters positively identified fluorescent dye traveling from lymphatics to epineurial CSF vessels in 75\% of responses (Figure 4b). Fisher's Exact Probability was significant with $\mathrm{p}<.0001$. Inter-observer agreement was good between raters 1 and 2 , and perfect $($ Kappa $=1)$ for raters 2 and 3 (see APPENDIX A).

\section{Do epineurial CSF vessels express a biomarker?}

Epineurial CSF vessels in all 28 median nerve specimens expressed vimentin (14f/14 male; ages 52 to 95 years; mean 72.3). A representative section is shown (Figure 5). 
medRxiv preprint doi: https://doi.org/10.1101/2020.06.26.20141267; this version posted June 29, 2020. The copyright holder for this preprint (which was not certified by peer review) is the author/funder, who has granted medRxiv a license to display the preprint in perpetuity.

All rights reserved. No reuse allowed without permission.

\section{Is vimentin a reliable biomarker for perineurial CSF vessels?}

\section{Raters' ability to identify perineurial fluorescence was reliable using vimentin}

compared to either LYVE-1 or podoplanin using 8 median nerve specimens $(2 \mathrm{f} / 6 \mathrm{~m}$; ages 29 to 83 years; mean 75.3 ). The F-test suggested the 3 groups were significantly different $(\mathrm{f}=30.7 ; \mathrm{df} 1=2 ; \mathrm{df}=14 ; \mathrm{p}<.0001 ;$ APPENDIX A). For added confirmation, perineurial fluorescence was compared using vimentin vs. LYVE-1 by averaged triplicate images of a region of interest $(\mathrm{ROI})$. Vimentin was statistically superior to LYVE-1 $(\mathrm{p}<.0001$, see APPENDIX A). Figure 6 shows a representative nerve section.

\section{Can we identify the CSF circulation of human brain by anatomic dissection?}

\section{Both dural and arachnoid CSF vessels were identified in 13 cranial dissections}

(8f/5m; ages 58 to 93 years; mean 72). Dural and arachnoid CSF vessels are clearly visible (Figure 7a). Dural CSF vessels may exit the skull through foramina (Figure 7b) and communicate with lymphatics at sites of periosteal fixation such as the nuchal ridge (Figure 7c). The main CSF channel in the sagittal sinus is identified (Figure 7d).

\section{What is the terminal CSF drainage from the human brain?}

We identified terminal CSF draining vessels within the carotid sheath in all 13

anatomic dissections ( $8 \mathrm{f} / 5 \mathrm{~m}$; ages 35 to 87 years; mean 58.7). Cervical CSF vessels exit the skull through the CSF foramen, and travel along posterior internal jugular vein to the thoracic duct (Figure 8a). Osteotomies enabled us to dissect an enbloc specimen of the intra-cranial CSF system (from temporal fossa) in continuity with the cervical drainage system (Figure $8 b$ ). 


\section{Does CSF drain from the brain to thoracic duct?}

Continuity between the intra-cranial and the extra-cranial CSF circulation and the superiority of fluorescent dye for visualization was documented in all 8 cadaver preparations (7f/1m; ages 40 to 95 years; mean 87.6$)$. Three raters were unable to identify visible dye traveling from the neck to the temporal fossa using visible dye and ambient light (Figure 9a). The same raters positively identified fluorescent dye after cervical injection traveling to the temporal fossa in $87.5 \%$ of their responses (Figure 9b). This was statistically significant with $\mathrm{p}<.0001$ (Kappa $=1$ for all observers).

\section{What additional biomarkers are expressed by the CSF circulatory system?} CSF vessels in human nerve express F-actin; GLUT-1; Claudin 1/3; and Ncadherin. GLUT-1 expression was noted in endocortical CSF vessels, arachnoid CSF vessels, dura, and perineurial CSF vessels. This could be the structural correlate to the physiological blood-brain barrier (Figure 10).

\section{Results are summarized in Table 1.}

\section{DISCUSSION}

Evidence suggests a novel CSF circulatory system exists in all human nerves. To our knowledge no prior manuscript, textbook, or atlas has identified any vessels on either peripheral or central nerves with the exception of arteries and veins. ${ }^{2-22}$ The human nervous system is devoid of lymphatics. ${ }^{2-22}$

Characteristics of the CSF circulatory system on nerves include the following (Table 1): 
1. CSF vessels exist in all layers of nerve (and brain);

2. Primary CSF drainage in humans is to thoracic duct;

3. Secondary CSF drainage exists to lymphatics;

4. CSF vessels can be distinguished from blood vessels/lymphatics; and

5. Biomarkers may include vimentin, GLUT-1, and F-actin.

CSF vessels are distinct from blood vessels and lymphatics. CSF vessels lack valves, unlike blood vessels and lymphatics. The CSF circulatory system is redundant on several levels, a design that helps regulate pressure and flow. Primary drainage is to thoracic duct; secondary drainage to lymphatics. In addition, perineurial CSF vessels can bypass epineurium to drain into lymphatics. The same bypass is found in human brain and in spinal cord (Figure 11).

CSF vessels do not express any known lymphatic or vascular biomarkers. ${ }^{27-31}$ This is in contrast to Loveau et al's work that characterized CSF vessels in mouse dura as lymphatics. ${ }^{32}$ Inter-species differences may exist. Human CSF vessels do not express glial fibrillary acidic protein (GFAP) in any layer of nerve or brain, and can not be characterized as glymphatic vessels found in mouse cortex by Iliff et al. ${ }^{33}$ Human CSF vessels express vimentin, a type-3 neurofilament protein usually expressed by cells of mesenchymal lineage. ${ }^{34}$ Another study suggests human perineurium expresses F-actin, vimentin, and GLUT-1, but those investigators were unable to identify CSF vessels. ${ }^{35}$ 
Much of the CSF circulatory system in the human brain can be visualized without magnification. Cerebrospinal fluid in the brain drains from sinus $\rightarrow$ falx $\rightarrow$ temporal fossa. The major CSF vessel on either side of the sagittal sinus is easily identified (Figure 7a). CSF ultimately drains into a plexus of vessels located within the temporal fossa (Figure 9a). The authors initially used loupes, micro-instruments, and the operating microscope to facilitate dissection. So it was a surprise (and humbling) to learn that much of the human CSF circulatory system had been identified over 200 years ago.

A case of lost and found

We did our historical review at Harvard's Countway Medical Library (Historical Medicine Section) and reviewed atlases by Cruickshank, Mascagni, and Poirier. ${ }^{2-4,7}$ Mascagni writes as follows (1787):

Ut notrae vasorum lymphaticorum ichnographiae quod licuit, complementum accederet in postrema hac Tabula, quod in dura \& pia meninge, \& arachnoide, in cerebri, \& cranii basi nobis occurrit... Occasione verò, qua alia figura vasorum cerebri, \& meningum truncos juxta vasa sanguinea dexteri lateris e cranio prodeuntes, ac per collum excurrentes demonstrantur...in ultima icone totius sysematis terminus in venarum subclviae \& internae utriusque lateris concursum re praefentatur.

This translates as follows:

"(That) our illustration of the lymphatic vessels nears completion in the final Table, and that (the lymphatic vessels) in dura, pia, and arachnoid meninges of the brain meet in the cranial base... However occasionally (as seen in) the other figure of cerebral (blood) 
vessels these meningeal vessels surround the right lateral vein (sic) and exit from the brain to demonstrably travel along the neck. This entire system ultimately drains into the (confluence) of the subclavian and internal jugular veins".

The vessels described by Mascagni ( and by Cruickshank and Poirier) are the CSF circulatory system of the human brain. ${ }^{2-4,7}$ Mascagni identified much of the CSF circulatory system in the human brain:

(1) CSF vessels are present in all meningeal layers;

(2) CSF vessels travel on the walls of blood vessels;

(3) CSF vessels form a plexus in the temporal fossa; and

(4) The entire CSF circulation of the human brain drains into thoracic duct. ${ }^{3,4}$

Mascagni’s only error was to characterize CSF vessels as lymphatics, most likely because their terminal drainage is thoracic duct (the known terminal drainage of all lymphatic vessels since Eustachius' initial description in 1533). Mascagni, like many other investigators including ourselves, tried to characterize these novel vessels in terms of what was already known.

\section{Clinical implications}

Evidence that a novel CSF circulatory system exist in human nerves may lead to improved understanding of nerve disorders, diseases, and basic anatomy. Nerve recovery 
after transection; nerve compression syndromes; perineurial invasion by tumor; and anatomical concepts are briefly discussed in light of these findings.

Nerve recovery after transection

Microsurgical nerve repair does not re-establish distal CSF circulation. The most devastating injuries are those involving the endoneurium, the terminal CSF drainage to axons. This may explain Wallerian degeneration (degeneration of axons distal to the site of injury). In addition, acute nerve transection may lead to increased intra-neural pressure due to CSF outflow obstruction: a form of compartment syndrome. ${ }^{36}$ Proximal nerves exhibit the worst recovery after repair; proximal nerves carry the greatest CSF volume; and proximal nerves are at the greatest risk for intra-neural compartment syndrome after transection. This has enormous implications for spinal cord repair.

\section{Nerve compression syndromes}

The hand surgeon will understand the implications of Figure 2b, where the largest vessels capable of decompressing antegrade CSF flow are found proximal to potential sites of nerve compression (wrist, elbow, neck). An ancillary finding was noted repeatedly: nerves can be compressed by lymphatic networks not associated with known areas of compression (Figure 12). This may explain residual symptoms after nerve release.

\section{Perineurial nerve invasion by tumor (PNI)}

Clinicians are familiar with the propensity of "neurotropic" tumors (e.g. adenoid cystic carcinoma, melanoma, breast cancer) to invade and migrate proximally along nerves. ${ }^{8-10}$ 
Research suggests tumor cells invade nerves along a path of least resistance. ${ }^{8-10,13,14}$ This concept reconciles the tissue layers involved but not the direction of tumor propagation (toward the CNS). The Heldermon Lab created a model of PNI in which immortalized breast cancer cells are injected in rat hind limb. Sciatic nerve biopsy confirms tumor cells invade perineurium and migrate proximally. In addition, tumor cells closely abut and travel along perineurial CSF vessels (Figure 13). A testable hypothesis is that tumor cells are biologically "attracted" to CSF and migrate proximally towards the highest concentration (i.e. the CNS) of some factor: if this is correct, interruption of CSF flow would result in diminished proximal invasion by tumor cells.

\section{Basic anatomical concepts}

Two basic anatomical tenets need to be revised and/or amended. (1) Sappey's Rule should be amended from an absolute to a relative criterion to characterize a novel vessel as lymphatic. ${ }^{6}$ (2) The current anatomical definition of the carotid sheath should be expanded to include a $4^{\text {th }}$ structure: the terminal CSF drainage of the brain. The proximity between internal jugular (IJ) vein and the CSF drainage of the cerebral hemisphere suggests caution when dissecting the IJ during vascular and microsurgical procedures.

\section{Sites of periosteal fixation and dural CSF drainage}

Loveau et al observed that dural (intra-cranial) CSF vessels drain directly to subcutaneous lymphatics along the sagittal sinus in mice, a novel finding. ${ }^{32}$ Loveau's work enabled us to identify dural CSF vessels exiting through discrete foramina to drain into subcutaneous lymphatics. Dural CSF vessels (within the cranium) communicate with 
subcutaneous lymphatics at other sites of periosteal fixation, for example the temporal crest and nuchal ridge. A re-appraisal of the anatomy of periosteal fixation, pioneered by Knize, may be warranted. ${ }^{37,38}$

\section{The blood-nerve and blood-brain barriers}

The blood-nerve and the blood-brain barriers have been the focus of intense research, yet their definitive location and structure has yet to be idenfied. ${ }^{35,}{ }^{39-41}$ Perineurium expresses the insulin-dependent glucose-1 transporter protein (GLUT-1), and has been suggested as the site of blood-nerve interaction. ${ }^{28}$ We can identify GLUT-1 positive CSF vessels in perineurium and arachnoid (Figure 14), suggesting these vessels as the structural analogue of the blood-nerve and blood-brain barrier. ${ }^{42}$

\section{Ancillary findings}

Many additional observations were made during the course of this 5-year study. Three of the more relevant are presented as they relate to aesthetic, cleft lip, and plastic surgery.

The white roll of the lip is determined by a lymphatic vessel

The anatomy of the white roll has been investigated by others. ${ }^{43}$ IR imaging identified a major lymphatic beneath the white roll of the upper lip. This is easily identified by anatomic dissection. 
Lymphatic vessels determine the location of static, dynamic, and senile wrinkles

IR imaging identified lymphatics beneath the nasolabial crease, the junction of fat compartments, and rhytides. Additional evidence suggests all wrinkles are located over lymphatic vessels, regardless of their designation as static, dynamic, senile and/or involutional.

Injectables travel further than what is observed using ambient light

Our experience with IR imaging suggests the following: observation of injections using ambient light always underestimates the true extent of diffusion. ${ }^{44}$ The complications of neck weakness, dysphagia, and dysphonia after chemodenervation are directly related to this observation.

\section{Limitations of this study}

Although preliminary flow studies suggest arachnoid CSF travels to endoneurial CSF vessels, this requires additional work. The strength of this study is the anatomy. This work was completed in early 2017, and since then the first author has received additional training in molecular biology. Our ability to image CSF vessels has advanced considerably such that CSF vessels in all layers can now be imaged with greater precision.

Vessels in the human CSF circulatory system are very different from blood vessels and lymphatics. They represent a distinct type of vessel(s). Our observations suggest possible homology with the vascular circulatory system of plants. 


\section{Xylem and phloem}

When forced to conclude that we were seeing a novel type of vessel, we searched elsewhere in biology for a potential analogue system; and thought of xylem and phloem. Plants may express F-actin and vimentin exactly like vessels in the human CSF circulatory system. ${ }^{51-53}$ Phloem channels represent a sucrose-transport system; CSF vessels a glucose-transport system. ${ }^{54}$ Even more intriguing, the circulatory system of plants may express a biomarker for human blood vessels (CD105; Figure 15). The authors have additional evidence of biological and structural homology that is outside the scope of this manuscript.

Every part of the human CSF circulation will require additional investigation. Since the completion of this body of work in early 2017, it has become clearer that priangeo vessels are structurally distinct from blood vessels and lymphatics. Our current work characterizes them as a system cells capable of inter-cellular fluid transfer (Figure 16). Future studies will provide the evidence for this structural concept. This paper was written for the clinical surgeon, and especially for the junior clinical plastic surgeon in hopes of stimulating their interest in this research. The study of the human CSF circulatory system is a field in its infancy, and the well-trained and motivated plastic surgeon can play an important role in its development.

\section{CONCLUSION}

\section{Evidence suggests a novel CSF circulatory system exists in all human nerves.}




\section{MATERIALS AND METHODS}

All antibodies and fluorescent dyes were acquired from Sigma Aldrich, USA unless stated otherwise. AlexaFluor ${ }^{\mathrm{TM}}$ secondary antibodies were used (Invitrogen, Carlsbad, CA). Antibodies were verified against human tissues prior to use (e.g. lymphatic antibodies tested against salivary gland). Dilutions were by titration. Positive samples were tested against negative controls (secondary antibody only). Fixation was by acetone, or by paraformaldehyde + antigen retrieval using HIER (citrate buffer). Sectioning followed graded sucrose preservation. All imaging was done using the Nikon AR-1 multi-photon microscope in confocal mode.

\section{Are epineurial CSF vessels present on all nerves?}

Twenty seven $(\mathrm{N}=54)$ upper extremities were dissected using the Leica M525 operating microscope (Leica Microsystems, Jena, Germany). The anatomy of epineurial CSF vessels on median and ulnar nerves was evaluated from carpal canal to thoracic outlet.

\section{Do epineurial CSF vessels have a defined lumen?}

Epineurial CSF vessels were identified in the median nerve of 10 upper extremity dissections. Direct intra-luminal injection was performed using various dyes including India ink, indocyanine green, and fluoroscein isothiocyanate (FITC). Results were documented. 


\section{Do epineurial CSF vessels drain into thoracic duct?}

A series of 13 hemi-thoracic (extremity/thorax/neck in-continuity) dissections were performed to identify the terminal drainage of CSF from nerves. The brachial plexus was dissected in each specimen, from which CSF communicating vessels traveling from nerve to the thoracic duct were noted. Fluorescent imaging was used to confirm flow to the thoracic duct in selected specimens.

\section{Do epineurial CSF vessels drain into lymphatics?}

Eight upper extremity dissections were prepared by isolating the median nerve at the wrist. A lymphatic vessel was identified (traveling away from the nerve) and injected (retrograde) using both visible dye and infrared fluorescent dye. The ability of 3 raters to identify dye traveling from the lymphatic to an epineural channel on the nerve was evaluated using visible vs. infra-red imaging. Results were compared using Fisher's Exact Probability Test.

\section{Do epineurial CSF vessels express a biomarker?}

Immunohistochemistry using the known lymphatic biomarkers PROX-1, FOXC2, podoplanin, LYVE-1 failed to define epineurial CSF channels. Vimentin was identified as a candidate biomarker. 1-step direct immunohistochemistry was performed using antivimentin antibody (V9 clone conjugated to Cy5) on 28 median nerve specimens that were subsequently imaged with confocal laser microscopy. 
medRxiv preprint doi: https://doi.org/10.1101/2020.06.26.20141267; this version posted June 29, 2020. The copyright holder for this preprint (which was not certified by peer review) is the author/funder, who has granted medRxiv a license to display the preprint in perpetuity.

All rights reserved. No reuse allowed without permission.

\section{Is vimentin a reliable biomarker for perineurial CSF vessels?}

We statistically compared the ability of 3 raters to identify perineurial CSF vessels using anti-vimentin antibody compared to the common lymphatic biomarkers LYVE-1 and podoplanin. Eight median nerve specimens were tested using 2-step indirect immunohistochemistry and triplicate hard copy images generated. Statistics were tested with a linear mixed effects model using the F-Test.

\section{Can we identify the CSF circulation of human brain by anatomic dissection?}

We performed gross anatomic dissections in 8 cranial specimens in a non-washout model to preserve filling of blood vessels. Dural and arachnoid CSF vessels were noted.

\section{What is the terminal CSF drainage from the human brain?}

We attempted to define CSF drainage vessels traveling from the skull to the thoracic duct in 13 cadaver dissections (thorax/neck/cranium in-continuity). The right thoracic duct was identified: A CSF vascular plexus (a group of CSF vessels) was found to terminate in the thoracic duct, after which it was dissected cephalad to the cranial base (i.e. known to unknown; retrograde). Anatomical relationships were noted.

\section{Does CSF drain from the brain to thoracic duct?}

This series includes 8 complete dissections (thorax/neck/cranium in continuity). The cervical CSF system was cannulated. Simultaneous craniotomy identified the terminal intra-cranial CSF plexus within the temporal fossa. Visible and infrared dyes were injected from the neck towards the brain. The ability of 3 raters to identify dye traveling 
from the extra-cranial to the intra-cranial CSF system was evaluated using visible light vs. infra-red imaging. Results were compared using Fisher's Exact Probability Test.

\section{What additional biomarkers are expressed by the CSF circulatory system?}

We discuss our observations over 5 years using ancillary biomarkers to identify CSF vessels in nerves, within the neck, and in the brain.

\section{ACKNOWLEDGEMENTS}

The authors thank the donors and families of the UTSW Willed Body Program.

The authors thank the nurses of Zale Lipshy operating room for their help.

All molecular imaging was performed at the McKnight Brain Institute.

Susan Frost PhD allowed us to use UFH-001 immortalized breast cancer cell line.

Special thanks to UF and all the researchers who contributed to this study.

\section{FUNDING}

The Gatorade Trust supports biomedical research at the University of Florida

This work was supported by NIH Grant IS1OD020026

This work was completed in the Heldermon Lab at University of Florida

\section{CONFLICTS OF INTEREST}

No conflict of interest is reported 


\section{REFERENCES}

1. Pessa JE, Kenkel JM, Heldermon CD. Periorbital and temporal anatomy, "Targeted fat grafting", and how a novel circulator system in human peripheral and central nerves may help avoid nerve injury and blindness during routine facial augmentation. Aesthet Surg J 2017:37;969-973.

2. Cruickshank WC. The anatomy of the adsorbing vessels of the human body. London, England: G Nicoli; 1786.

3. Mascagni P. Vasorum Lymphaticorum Corporis Humani. Siena, Italy: Pazzini Carli; 1787. Tabula XXVII.

4. Mascagni P. Anatomia Universale. Florence, Italy: Torchi di V, Batelli E Figli; 1833. Table IX.

5. Swalbe G. The arachnoid space with the lymph space and perichoriodal space (German). Zbl Med Wiss 1869:7;465-467.

6. Sappey MPC. Anatomie, Physiologie, Pathologie des vaisseaux lymphatiques consideres chez l'homme et les vertebre. Paris: A. Delahaye and E. Lecrosnier; 1874.

7. Delemere G, Poirier P, Cuneo B. The lymphatics. Chicago: WT Keener and Company; 1904. 
8. Shattock SG. Invasion of the nerves in carcinoma of the sublingual salivary gland associated with carcinoma of the tongue. Proc R Soc Med 1921:15;13-16.

9. Moore RA. The morphology of small prostatic carcinoma. J Urol 1935:33;224-234.

10. Warren S, Harris PV, Graves RC. Osseous metastases of carcinoma of the prostate with special reference to the perineural lymphatics. Arch Pathol 1936:22;138-160.

11. Sunderland S. A classification of peripheral nerve injuries producing loss of function. Brain 1951:74;491-516.

12. Sunderland S, Bradley KC. The perineurium of peripheral nerves. Anat Rec $1952: 113 ; 125-141$

13. Alfonso De La Pena, Ecsudero PB, Oliveros M. Carcinoma of the prostate and perineural lymphatic invasion. 1960:35;36-41.

14. Ballantyne AJ, McCarten AB, Ibanez ML. The extension of cancer of the head and neck through peripheral nerves. Am J Surg 106:1963;651-667.

15. Sunderland S. The connective tissue of peripheral nerves. Brain 1965:88;841-853. 
16. Larson DL, Rodin AE, Roberts DK, O’Steen WK, Rapperport AS, Lewis SR.

Perineural lymphatics - Myth or fact. Am J Surg 1966:112;488-492.

17. Rodin AE, Larson DL, Roberts DK. Nature of perineural space invaded by prostatic carcinoma. Cancer 1967:20;1772-1779.

18. Peters A, Palay SL, Webster HF. The fine structure of the nervous system.

Philadelphia: WB Saunders, 1976; p. 323-331.

19. Hassan MO, Maksem J. The prostatic perineural space and its relation to tumor spread. Am J Surg Pathol 1980:4;143-148.

20. Sunderland S. The anatomy and physiology of nerve injury. Muscle and Nerve 1990:13;771-774.

21. Schrödl F, Kaser-Eichberger A, Trost A, et al. Lymphatic markers in the adult human choroid. Invest Ophthal and Vis Sci 2015:56;7406-7416.

22. Kaser-Eichberger A, Schroedl F, Bieler L, et al. Expression of lymphatic markers in the adult rat spinal cord. Frontiers in Cell Sci 2106:10;1-10. 
23. Suami H, Taylor GI, O’Neill J, Pan WR. Refinements of the radiographic cadaver injection technique for investigating minute lymphatic vessels. Plast Reconstr Surg 2007:120;61-67.

24. Suami H, Taylor GI, Pan WR. The lymphatic territories of the upper limb: anatomical study and clinical implications. Plast Reconstr Surg 2007:119;1813-1822.

25. Suami H, Scaglioni MF. Lymphatic territories (Lymphosomes) in the Rat: An anatomical study for future lymphatic research. Plast Reconstr Surg 2017:140;945-951.

26. Suami H, Scaglione MF. Anatomy of the lymphatic system and the lymphosome concept in reference to lymphedema. Semin Plast Surg 2018:32;5-11.

27. Jackson DG, Prevo R, Clasper S, Banerji S. LYVE-1, the lymphatic system and tumor lymphangiogenesis. Trends Immunol 2001:22:317-321.

28. Oliver G, Harvey N. A stepwise model of the development of lymphatic vasculature. Ann NY Acad Sci 2002:979;159-165.

29. Baluk P, McDonald DM. Markers for microscopic imaging of lymphangiogenesis and angiogenesis. Ann NY Acad Sci 2008: 1131;1-12. 
30. Oliver G, Srinivasan RS. Lymphatic vasculature development. Ann NY Acad Sci 2008:1131;75-81.

31. Chenggang Li, Huo B, Wilson PB, et al. Plasma levels of soluble CD105 correlate with metastasis in patients with breast cancer. Int J Cancer 2000:89:122-126.

32. Loveau A, Smirnov I, Keyes TJ, et al. Structural and functional features of central nervous system lymphatic vessels. Nature 2015:523;337-341.

33. Iliff JJ, Wang M, Liao Y, et al. A paravascular pathway facilitates CSF flow through the brain parenchyma and the clearance of interstitial solutes, including amyloid $\beta$. Sci Transl Med 2012:147;1-22.

34. Eriksson JE, Dechat T, Grin B, et al. Introducing intermediate filaments: from discovery to disease. J Clin Invest 2009;19:1763-1771.

35. Piña-Oviedo S, Ortiz-Hidalgo C. The normal and neoplastic perineurium. Ann Anat Pathol 2008:15;147-164.

36. Lundborg G, Myers R, Powell H. Nerve compression and increased endoneurial fluid pressure: a "miniature compartment syndrome". J Neurol Neurosurg Psych $1983: 46 ; 1119-1124$. 
37. Knize DM. The importance of the retaining ligamentous attachments of the forehead for selective eyebrow reshaping and forehead rejuvenation. Plast Reconstr Surg 2007:119;119-1120.

38. Knize DM. Anatomic concepts for brow lift procedures. Plast Reconstr Surg 2009:124;2118-2126.

39. Weerasuriya A, Mizisin AP. The blood-nerve barrier: structure and functional significance. Methods Mol Biol 2011:686;149-173.

40. Kanda T. Blood-nerve barrier: structure and function. Brain Nerve 2011:63;557-569.

41. Keaney J, Campbell M. The dynamic blood-brain barrier. FEBS J 2015:282;40674079 .

42. Kuehn BM. In Alzheimer research, glucose metabolism moves to center stage. JAMA 202:323;292-299.

43. Mulliken JB, Pensler JM, Kozakewich HP. Plast Reconstr Surg 1993:92;395-403. Discussion pg 404. 
44. How J, Gotlieb WH, Press JZ, et al. Comparing indocyanine green, technetium, and blue dye for sentinel lymph node mapping in endometrial cancer. Gyn Onc 2015:137;438-442.

45. Quincke H. On the physiology of cerebrospinal fluid. Arch Anat Physiol Lpz 1872:153-177.

46. Weed LH. Studies on the cerebro-spinal fluid. J Med Res 1914:31;21-117.

47. Olitsky PK, Cox HR, Syverton JT. Comparative studies on the viruses of vesicular stomatitis and equine encephalomyelitits. J Exp Med 1934:59;159-171.

48. Rake G. The rapid invasion of the body through the olfactory mucosa. J Exp Med 1937:65;303-315.

49. Miura M, Kato S, von Lüdinghausen M. Lymphatic drainage of the cerebrospinal fluid from monkey spinal meninges with special reference to the distribution of the epidural lymphatics. Arch Histol Cytol 1998:61;277-286.

50. Walter BA, Valera VA, Takahashi, Ushiki T. The olfactory route for cerebrospinal fluid drainage into the peripheral lymphatic system. Neuropath Applied Neurobiol 2006:32;388-396. 
51. Pesacreta TC. F-actin distribution in root primary tissues of several seed plant species. Am J Botany 2015:102;1422-1433.

52. Hargreaves AJ,Goodbody KC, Lloyd CW. Reconstitution of intermediate filaments from a higher plant. Biochem J 1989:261;679-682.

53. Hargreaves AJ, Dawson PJ, Butcher GW, Larkings A, Goodbody KC, Lloyd CW. A monoclonal antibody raised against the cytoplasmic fibrillary bundles from carrot cells, and its cross-reaction with animal intermediate filaments. J Cell SCi 1989:92;371-378.

54. Baker RF, Leach KA, Boyer NR, et al. Sucrose Transporter ZmSut1 expression and localization uncover new insights into sucrose phloem loading. Plant Phys 2016:172;1876-1898. 


\section{Question to be studied \#/Gender Ages Technique Findings or conclusions}

\begin{tabular}{|c|c|c|c|c|}
\hline $\begin{array}{l}\text { Are epineurial CSF vessels present } \\
\text { on all nerves? }\end{array}$ & $\begin{array}{c}11 \mathrm{f} / 16 \mathrm{~m} \\
(\mathrm{~N}=54)\end{array}$ & $\begin{array}{l}58-98 \\
(68.3) \\
\end{array}$ & $\begin{array}{l}\text { Microsurgical } \\
\text { dissection }\end{array}$ & $\begin{array}{l}\text { Epineurial CSF vessels are present } \\
\text { on all nerves }\end{array}$ \\
\hline $\begin{array}{l}\text { Do epineurial CSF vessels have a } \\
\text { defined lumen? }\end{array}$ & $\begin{array}{l}6 \mathrm{f} / 2 \mathrm{~m} \\
(\mathrm{~N}=8)\end{array}$ & $\begin{array}{l}46-97 \\
(76.6)\end{array}$ & $\begin{array}{l}\text { Direct injection } \\
\text { with dyes }\end{array}$ & $\begin{array}{l}\text { Epineurial CSF vessels have a } \\
\text { defined lumen }\end{array}$ \\
\hline $\begin{array}{l}\text { Do epineurial CSF vessels drain into } \\
\text { thoracic duct? }\end{array}$ & $\begin{array}{l}5 \mathrm{f} / 8 \mathrm{~m} \\
(\mathrm{~N}=13)\end{array}$ & $\begin{array}{l}54-92 \\
(74.3)\end{array}$ & $\begin{array}{l}\text { Dissection; } \\
\text { injection }\end{array}$ & $\begin{array}{l}\text { Epineurial CSF vessels drain } \\
\text { into thoracic duct }\end{array}$ \\
\hline $\begin{array}{l}\text { Does continuity exist with the } \\
\text { lymphatic system? }\end{array}$ & $\begin{array}{l}6 f / 2 m \\
(N=8)\end{array}$ & $\begin{array}{l}52-92 \\
(83.3)\end{array}$ & $\begin{array}{l}\text { Comparison } \\
\text { of IR imaging }\end{array}$ & $\begin{array}{l}\text { Continuity exists; infra-red } \\
\text { imaging superior } p<.0001\end{array}$ \\
\hline $\begin{array}{l}\text { Do epineurial CSF vessels express a } \\
\text { biomarker? }\end{array}$ & $\begin{array}{c}14 \mathrm{f} / 14 \mathrm{~m} \\
(\mathrm{~N}=28)\end{array}$ & $\begin{array}{l}52-95 \\
(72.3)\end{array}$ & $\begin{array}{l}\text { Immuno- } \\
\text { histochemistry }\end{array}$ & $\begin{array}{l}\text { Epineurial CSF vessels express } \\
\text { vimentin }\end{array}$ \\
\hline $\begin{array}{l}\text { Is vimentin a reliable biomarker } \\
\text { for perineurial CSF vessels? }\end{array}$ & $\begin{array}{c}2 \mathrm{f} / 6 \mathrm{~m} \\
(\mathrm{~N}=8)\end{array}$ & $\begin{array}{l}29-83 \\
(75.3)\end{array}$ & $\begin{array}{l}\text { Immuno- } \\
\text { histochemistry }\end{array}$ & $\begin{array}{l}\text { Vimentin superior to LYVE-1 } \\
\text { or podoplanin } p<.0001\end{array}$ \\
\hline $\begin{array}{l}\text { Can the cerebral CSF circulation } \\
\text { be visualized macroscopically? }\end{array}$ & $\begin{array}{l}8 \mathrm{f} / 5 \mathrm{~m} \\
(\mathrm{~N}=13)\end{array}$ & $\begin{array}{l}58-93 \\
(72.0)\end{array}$ & $\begin{array}{l}\text { Gross } \\
\text { anatomy }\end{array}$ & $\begin{array}{l}\text { Dural and arachnoid CSF } \\
\text { vessels observed }\end{array}$ \\
\hline $\begin{array}{l}\text { Does the cerebral CSF circulation } \\
\text { drain into the thoracic duct? }\end{array}$ & $\begin{array}{l}8 \mathrm{f} / 5 \mathrm{~m} \\
(\mathrm{~N}=13)\end{array}$ & $\begin{array}{l}35-87 \\
(58.7)\end{array}$ & $\begin{array}{l}\text { Retrograde } \\
\text { dissection }\end{array}$ & $\begin{array}{l}\text { Anatomical continuity from } \\
\text { Thoracic duct to cranial base }\end{array}$ \\
\hline $\begin{array}{l}\text { Does continuity exist between the } \\
\text { intra and extra cranial CSF circulation }\end{array}$ & $\begin{array}{l}7 \mathrm{f} / 1 \mathrm{~m} \\
(\mathrm{~N}=8)\end{array}$ & $\begin{array}{l}40-95 \\
(87.6)\end{array}$ & $\begin{array}{l}\text { Comparison } \\
\text { Of IR imaging }\end{array}$ & $\begin{array}{l}\text { Continuity exists; infra-red } \\
\text { Imaging superior } p<.0001\end{array}$ \\
\hline $\begin{array}{l}\text { What additional biomarkers are } \\
\text { expressed by the CSF circulation? }\end{array}$ & $\begin{array}{l}\text { Random } \\
\text { sampling }\end{array}$ & $28-98$ & $\begin{array}{l}\text { Immuno- } \\
\text { histochemistry }\end{array}$ & $\begin{array}{l}\text { CSF vessels express F-actin, } \\
\text { GLUT-1, Claudin } 1 / 3 \text {, cadherin }\end{array}$ \\
\hline
\end{tabular}

Table 1. Studies from a series of 150 fresh cadaver dissections performed to address

specific questions regarding the CSF circulatory system of human nerves (and brain). 


\section{CSF Vessels exist in all layers of nerves}
A. Epineurial vessels cover outer epineurium
B. Perineurial vessels: form a plexus within perineurium
C. Endoneurial vessels: surround axons

\section{The primary drainage of the CSF circulation on nerves is to thoracic duct}
A. Epineurial communications from nerve roots to thoracic duct
B. Epineurial communications from nerve roots to CSF drainage in neck

\section{Secondary drainage occurs to subcutaneous lymphatics}

\section{A. Epineurial CSF vessels drain to lymphatics}

1. Largest communications proximal to potential sites of nerve compression

B. Perineurial CSF vessels may drain directly to lymphatics

1. Potential valve to bypass injured epineurium

\section{CSF vessels may be distinguished from blood vessels and lymphatics}
A. Avascular: devoid of red blood cells
B. Lack valves
C. Exhibit side-to-side cellular junctions
D. Trans-membrane microfilaments noted on walls of CSF vessels

\section{Biomarkers}
A. Certain CSF vessels are F-actin+; vimentin+; GLUT-1+
B. Gap junction proteins include Claudin $1 / 3$; N-cadherin
C. All CSF vessels are PROX-1-; FOXC2-; LYVE-1-; POD-; D240-; VEGFR3-
D. CSF vessels do not express vascular markers: are CD34-; CD105- (endoglion)
E. Paravascular channels in human cortex are GFAP-

\section{CSF vessels often located in proximity to veins}

A. CSF vessels travel along veins between perineurium and endoneurium

B. Terminal CSF drainage from brain travels within adventia of internal jugular vein

Table 2. Features of the CSF circulatory system of human nerves. 


\section{CSF vessels exist in all layers of human brain}

A. Dural CSF vessels on undersurface of dura

B. Arachnoid CSF vessels

1. May communicate with dural CSF vessels

C. Cortical CSF vessels

1. Paravascular channels in human cortex are not glymphatics

2. Do NOT express GFAP

3. Discrete cortical CSF vessels can be identified Vim+

\section{Primary drainage of cerebral CSF circulation is to thoracic duct}

A. Terminal intra-cranial CSF system is a plexus

1. Located in temporal fossa

2. Exits cranial base through foramen

B. Cervical CSF vessels travel within carotid sheath

1. Travel on posterior internal jugular vein

2. Located within adventitia

\section{Secondary cerebral CSF drainage to lymphatics}

A. Direct dural CSF-subcutaneous lymphatics along sagittal suture

B. Other locations of dural CSF-subcutaneous lymphatics at points of fixation

\section{Biomarkers}
A. Arachnoid CSF vessels vimentin+
B. Human cerebral CSF vessels do not express lymphatic biomarkers
C. Paravascular channels in human cortex are GFAP-

\section{Some cerebral CSF vessels can be identified macroscopically}
A. Dural and arachnoid CSF vessels
B. Terminal intra-cranial plexus in temporal fossa

\section{Arachnoid CSF flow}
A. Enters sagittal sinus
1. Through arachnoid granulations
2. Through open pores along sagittal sinus
B. Flow from sinus to falx cerebri
C. Falx empties into terminal CSF plexus

Table 3. Features of the human cerebral CSF circulatory system. 


\section{FIGURE LEGENDS}

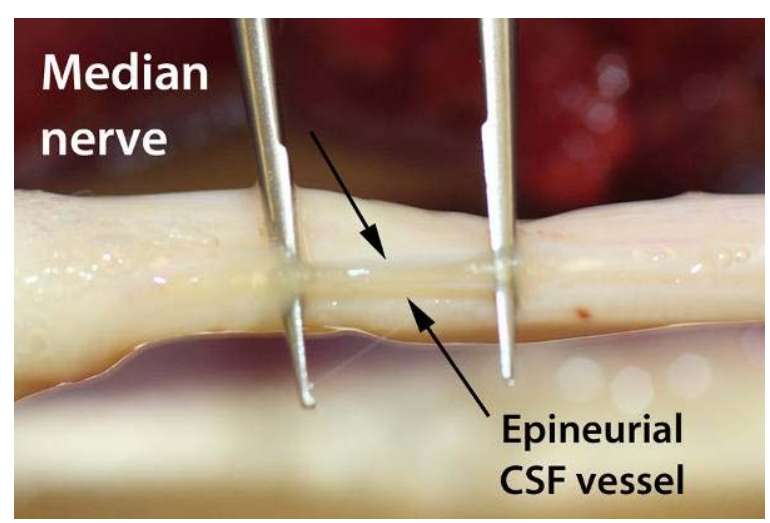

Figure 1a. Epineurial CSF vessel on median nerve have not been previously described.

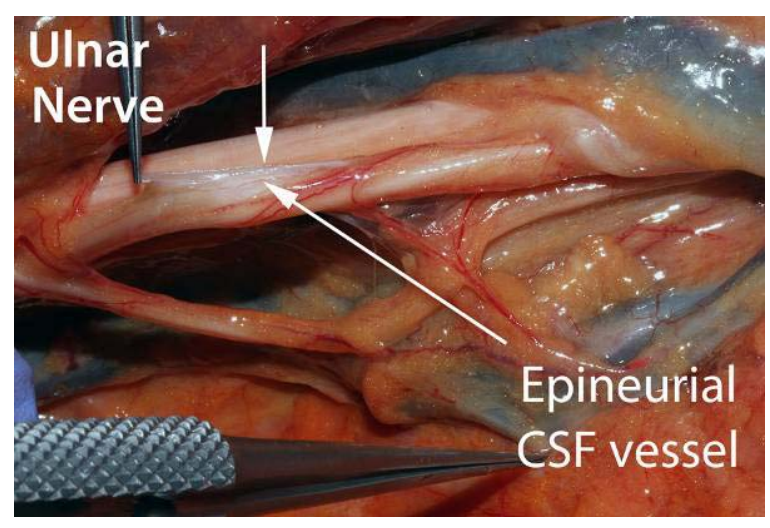

Figure 1b. Epineurial CSF vessel on ulnar nerve above the elbow.

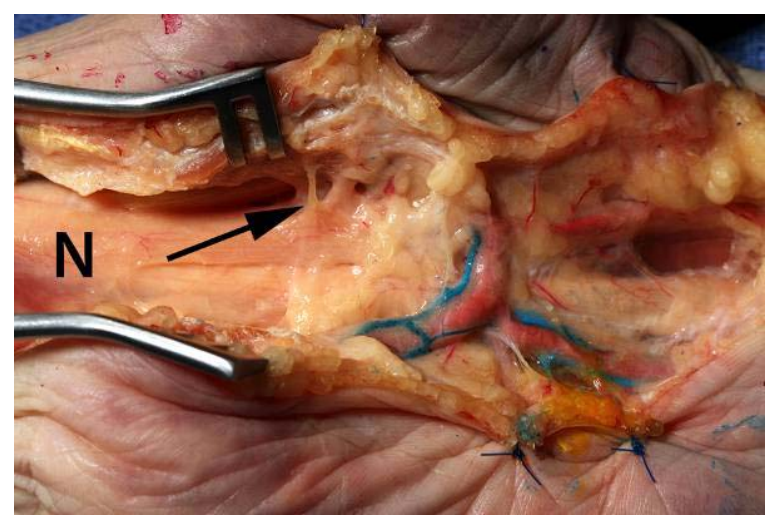

Figure 1c. Epineurial CSF vessels drain to lymphatics via communicating branches (arrow) just proximal to potential sites of anatomic nerve compression. Median nerve $(\mathrm{N})$ dissection in 67 year-old male specimen. 


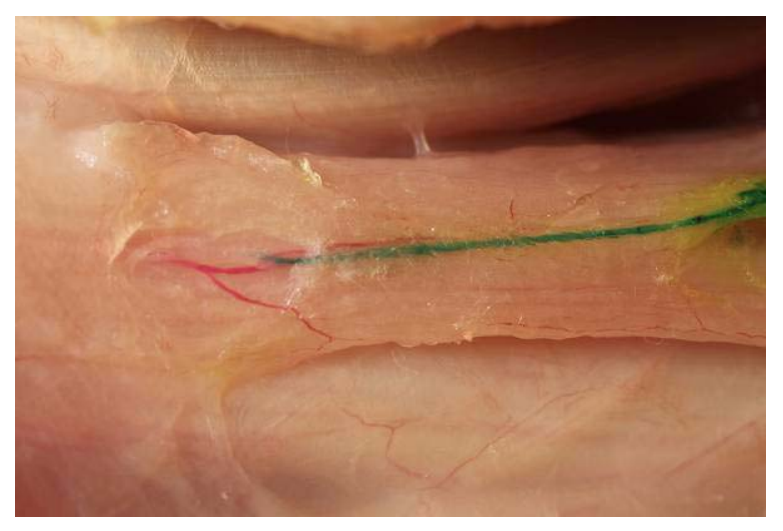

Figure 2. Injection of epineurial CSF vessel with green dye.

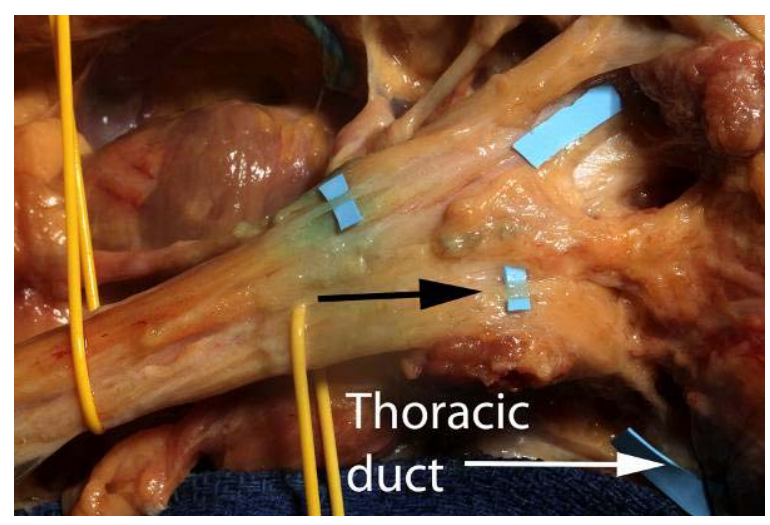

Figure 3a. Brachial plexus dissection in 54 year-old male cadaver shows epineurial CSF vessels (black arrow) traveling to thoracic duct. FITC confirmed flow.

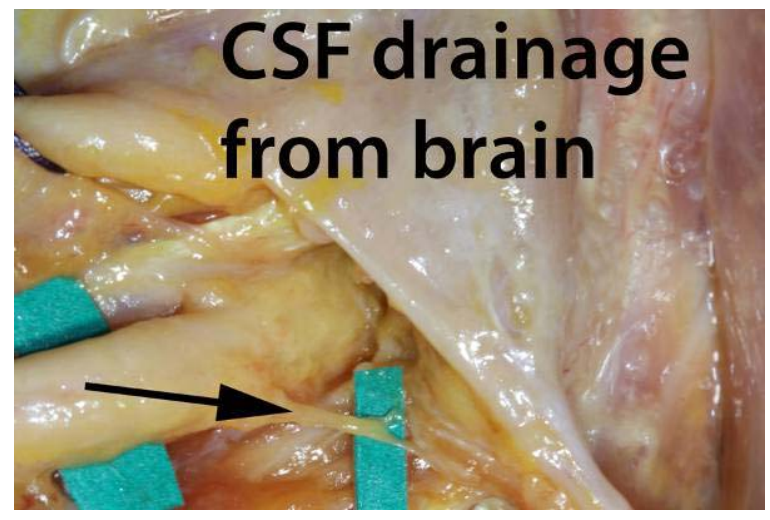

Figure 3b. In upper root levels, epineurial CSF vessels (black arrow) traveled first to the cervical CSF drainage of the brain (within the carotid sheath) prior to draining into thoracic duct. 40 year-old female dissection is shown. 


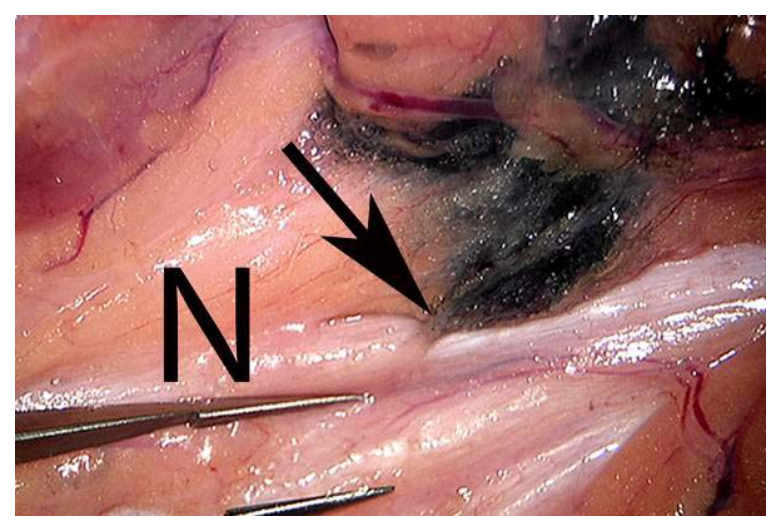

Figure 4a. Raters were unable to identify dye injected into a lymphatic traveling to epineurial CSF vessels on median nerve using ambient light in this 73 year-old female dissection.

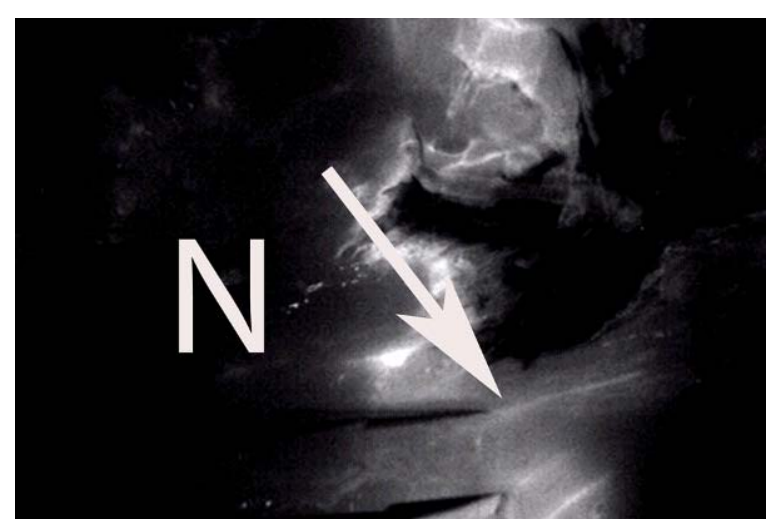

Figure 4b. Raters identified dye traveling from lymphatic to epineurial vessels (white arrow) used infra-red imaging in $75 \%$ of their responses.

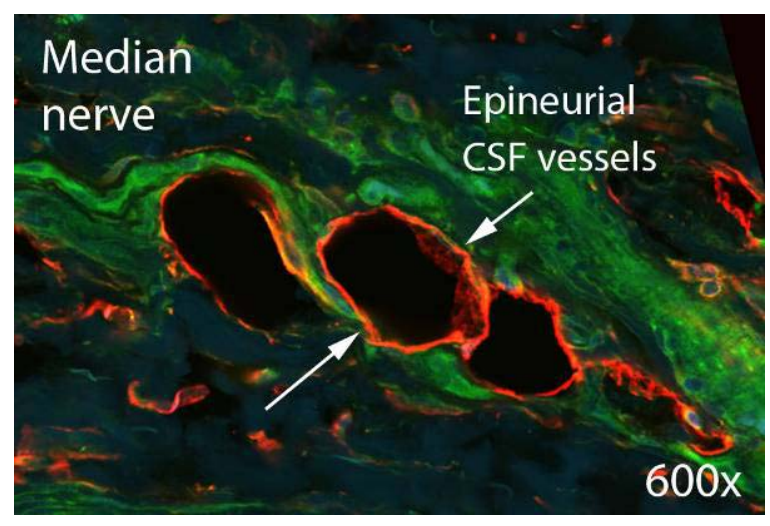

Figure 5. Epineurial CSF channels in median nerve from a 29 year-old female cadaver dissection are vimentin+. 


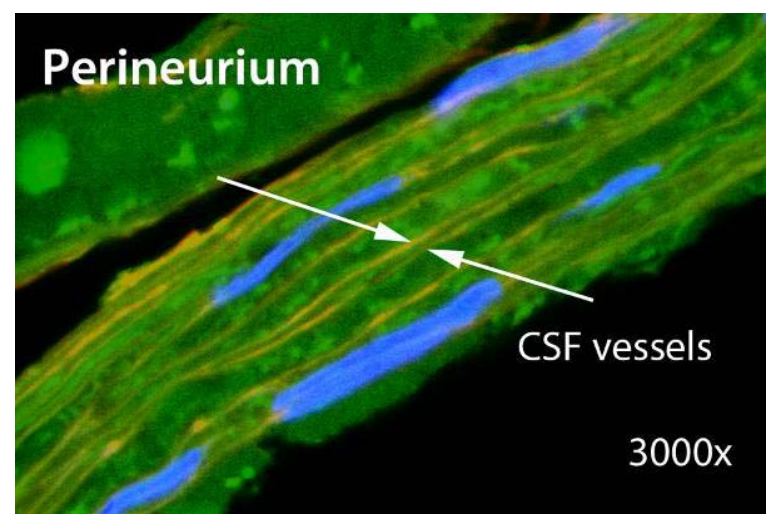

Figure 6. Perineurial CSF vessels are seen in median nerve at 3000x (Work from 2014).

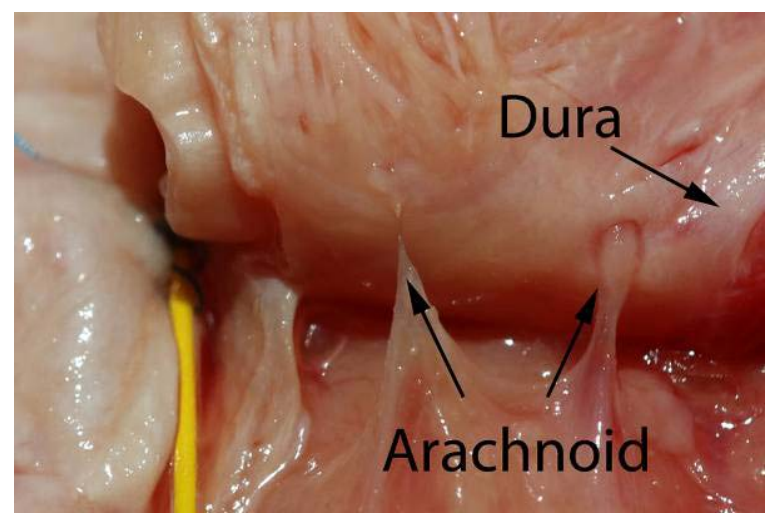

Figure 7a. In this 92 y/o female cranial dissection, CSF vessels can be seen on dura (arrow). Arachnoid

CSF vessels (arrow) travel to the dural CSF system with veins, a design that protects from shear.

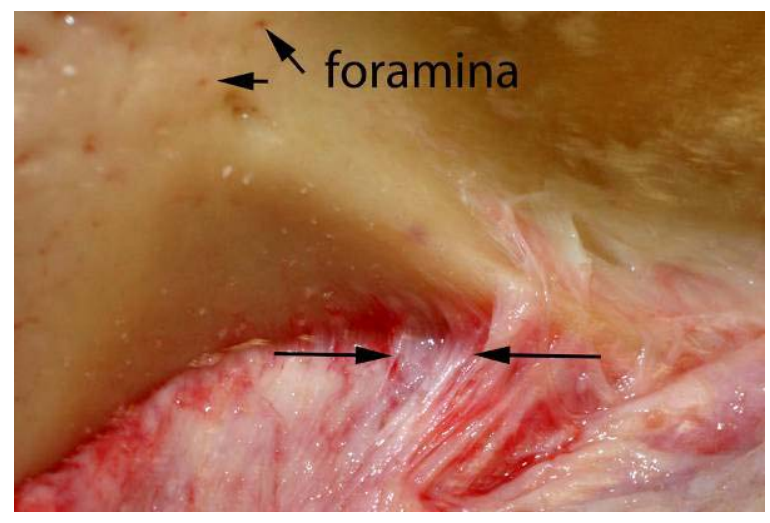

Figure 7b. Dural CSF vessels (arrows) travel through foramina in the skull, seen in the upper left of this image of this 74 year-old female dissection. 


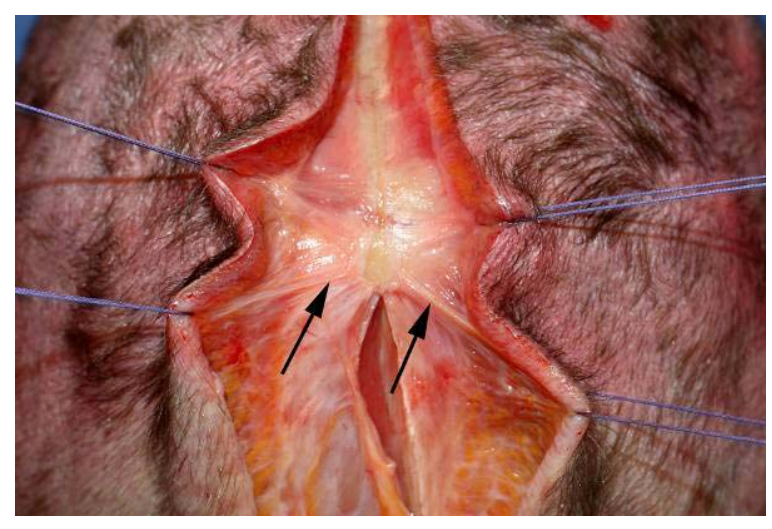

Figure 7c. Dural CSF vessels exit the skull at sites of periosteal fixation where they drain into lymphatics (arrows), as seen here at the posterior nuchal ridge.

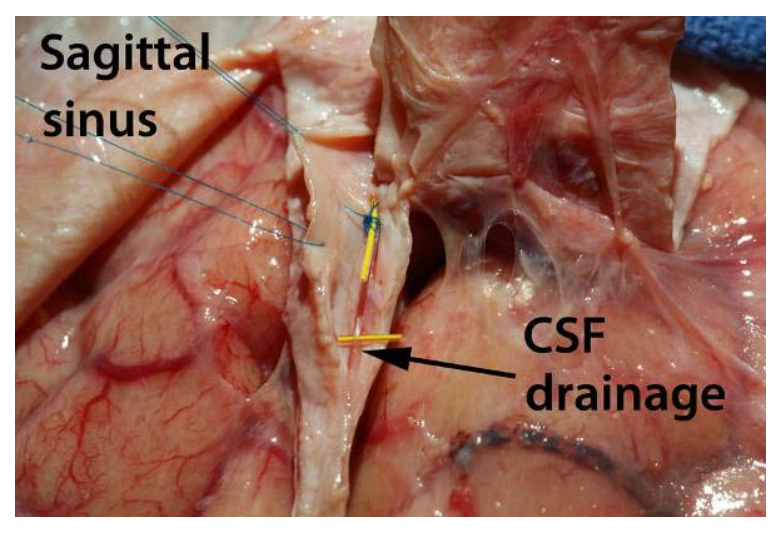

Figure 7d. The main CSF channel in the (right hemisphere) traveling in sagittal sinus.

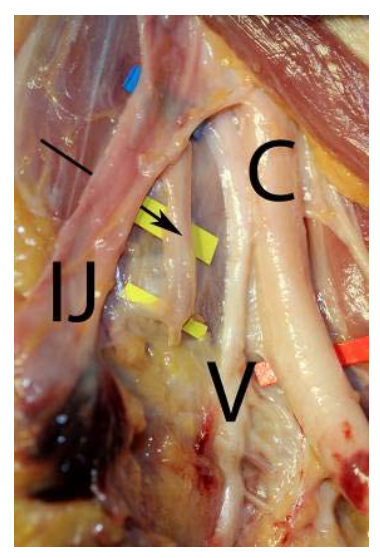

Figure 8a. The entire cerebral CSF circulation drains into a plexus of vessels (arrow) traveling along the posterior internal jugular vein (IJ). Carotid artery (C) and vagus nerve (V) are noted. 


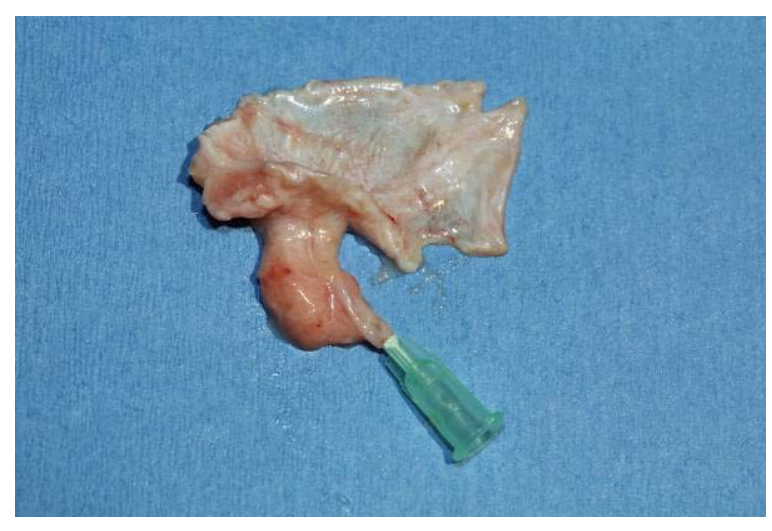

Figure 8b. Cervical CSF drainage (cannulated) is shown with intra-cranial CSF system.

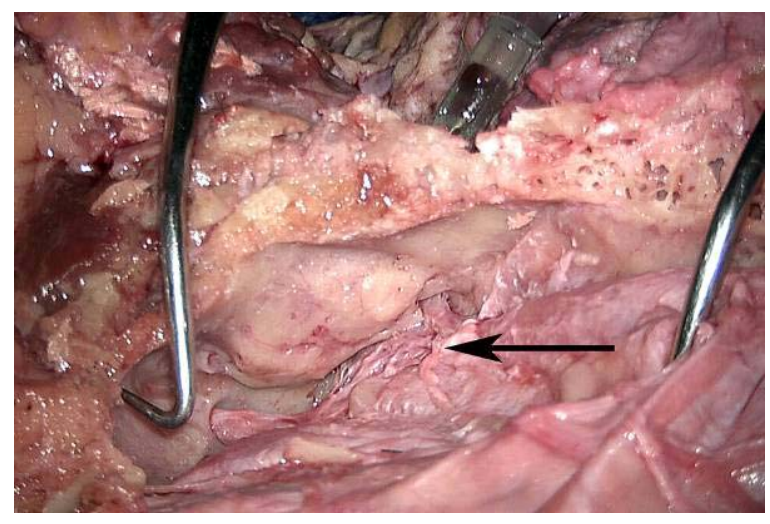

Figure 9a. Raters were unable to visualize dye injected from the neck traveling to the terminal intra-cranial

CSF circulation (arrow) using ambient light.

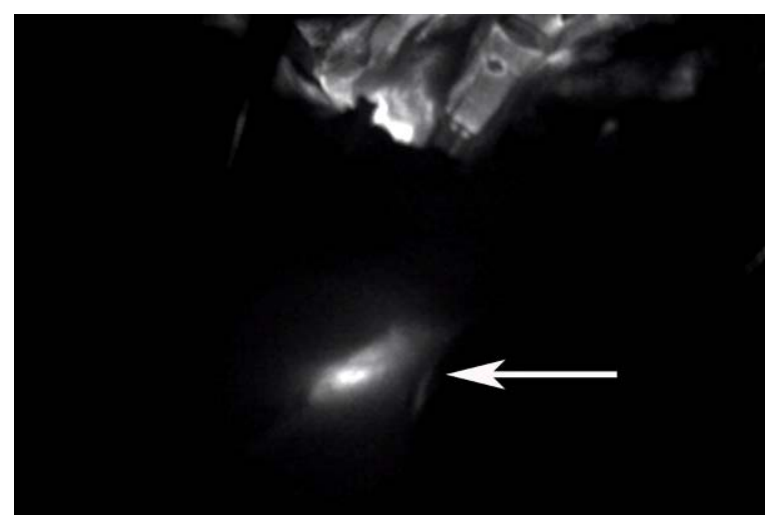

Figure 9b. Raters identified dye traveling traveling retrograde from the neck to the terminal intra-cranial

CSF system (arrow) in $87.5 \%$ of their responses. Note the syringe visible in upper photo containing IR800 dye. 


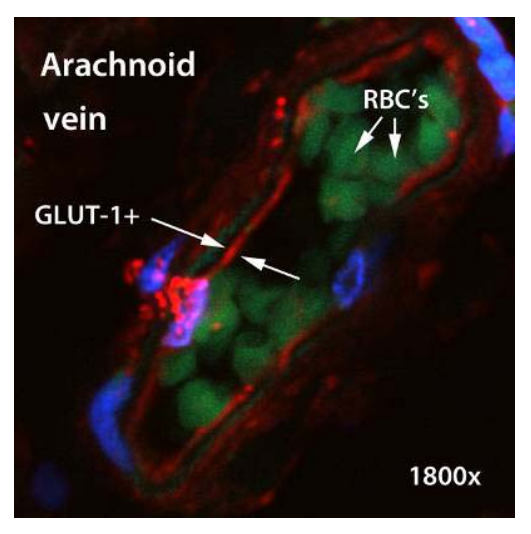

Figure 10. GLUT-1+ CSF paravascular channels in the wall of arachnoid vein are found in the human spinal cord. These CSF vessels represent the possible structural blood-brain barrier.

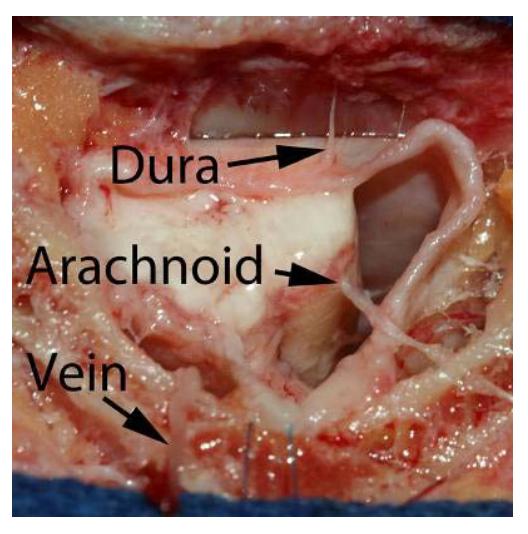

Figure 11. Redundancy of the human CSF circulatory system exists on several levels. Dural CSF vessels (arrow from dura) drain to subcutaneous lymphatics. Arachnoid CSF vessels can bypass dura (arrow from arachnoid) to drain directly into subcutaneous lymphatic vessels. 80 year-old male spinal cord dissection.

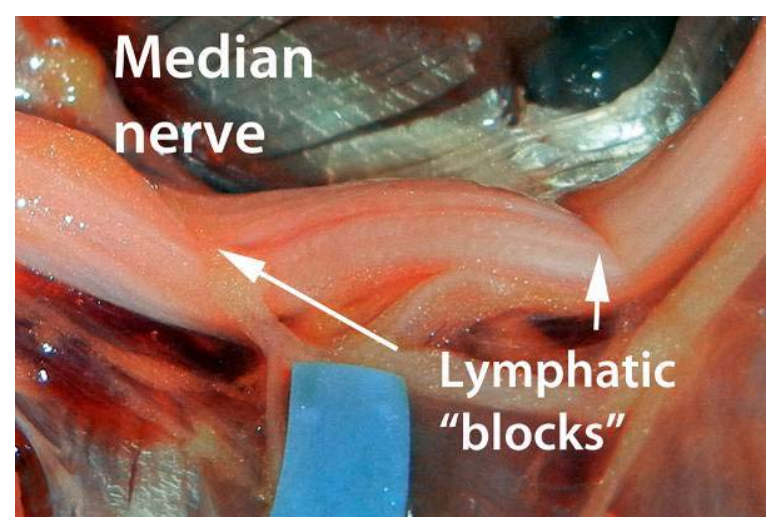

Figure 12. Median nerve compressed solely by a lymphatic plexus. 


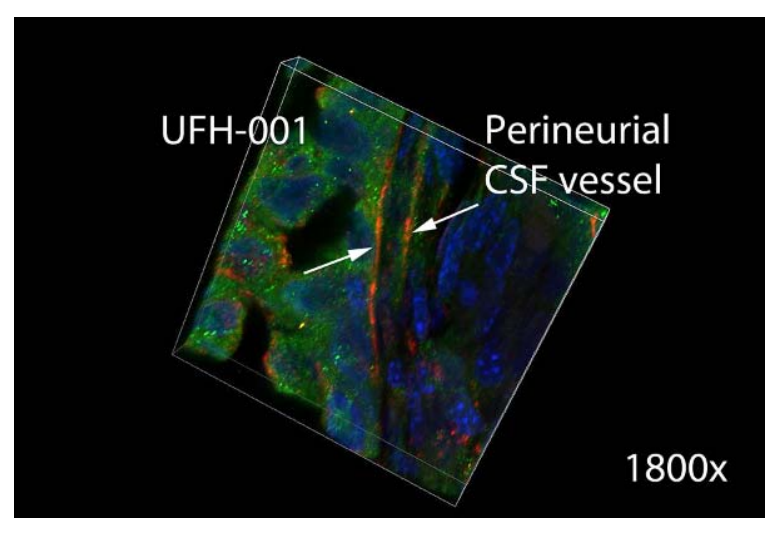

Figure 13. Immortalized breast cancer cells (Luciferase+ green) abut and travel along vimentin+ perineurial CSF channels (red fluorescence indicates vessel walls) in mouse sciatic nerve. 1800x. Volume view assembled from z-stack images $70.10 \mu \times 70.10 \mu \times 10 \mu$; images acquired at $0.2 \mu$ intervals, Weber deconvolution.

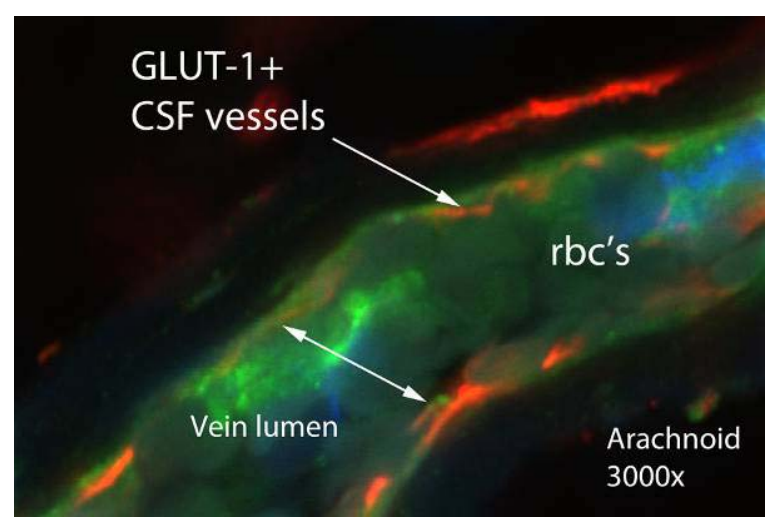

Figure 14. GLUT-1+ CSF vessels surrounding an arachnoid vein in human brain.

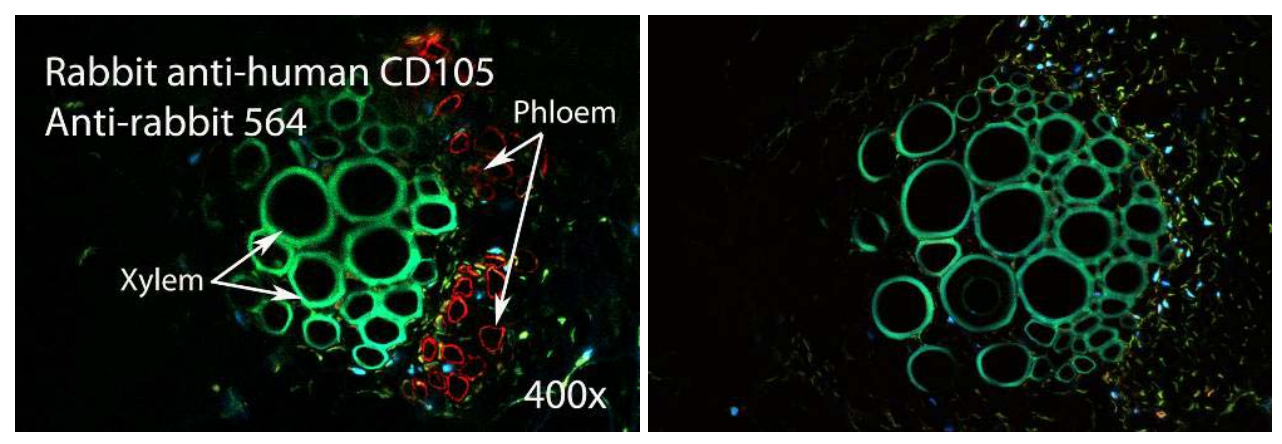

Figure 15. Carota daucus phloem channels test positive against anti-human CD105, a biomarker for human blood vessels. Right, negative control. 


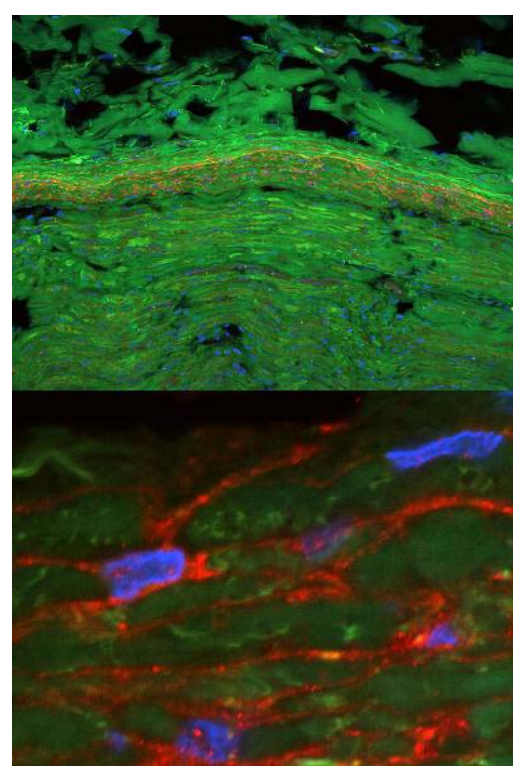

Figure 16, Top. The perineurium expresses the insulin-dependent glucose-1 transporter protein (red fluorescence) and is the likely structural analogue of the physiological blood-nerve barrier. Figure 16, Bottom. At 3000x, the walls of CSF vessels (priangeo vessels) express GLUT-1. Companion cells are located at the junction of multiple vessels. The morphology of CSF vessels suggests that circulatory flow is accomplished by inter-cellular fluid transfer.

\section{Joel E Pessa MD FACS}

\section{Florence Avenue}

Arlington, Massachusetts 02476

jpezza@protonmail.com

jepessa@gmail.com 